\title{
QUANTIFYING THE VEGETATION HEALTH BASED ON THE RESILIENCE IN AN ARID SYSTEM
}

\author{
ABOLFAZL RANJBAR ${ }^{1 *}$, MARZIEH TAABE ${ }^{2}$, SEIIED HOJJAT MOUSAVI ${ }^{3}$, MOHAM- $^{-}$ \\ MAD KHOSROSHAHI ${ }^{4}$
}

${ }^{1}$ Department of Desert Studies, Faculty of Natural Resources and Geosciences, University of Kashan, 8731753153 Kashan, Islamic Republic of Iran; e-mail: aranjbar@kashanu.ac.ir

${ }^{2}$ Department of Desert Studies, Faculty of Natural Resources and Geosciences, University of Kashan, 8731753153 Kashan, Islamic Republic of Iran; e-mail: marzieh.taabe@gmail.com

${ }^{3}$ Department of Geography and Ecotourism, Faculty of Natural Resources and Geosciences, University of Kashan, 8731753153 Kashan, Islamic Republic of Iran; e-mail: hmousavi15@kashanu.ac.ir

${ }^{4}$ Institute of Forest and Rangeland, Agricultural Research, Education and Extension Organization (AREEO), 1955756114 Tehran, Islamic Republic of Iran; e-mail: khosro@rifr.ac.ir

* Author for correspondence

\begin{abstract}
Ranjbar A., Taabe M., Mousavi S.H., Khosroshahi M.: Quantifying the vegetation health based on the resilience in an arid system. Ekológia (Bratislava), Vol. 37, No. 1, p. 32-41, 2018.

Proper management of natural ecosystems is not possible without the knowledge of the health status of its components. Vegetation, as the main component of the ecosystem, plays an important role in its health. One of the key determinants of vegetation health is its resilience in the face of environmental disorders. This research was conducted in parts of the Namakzar-e Khaf watershed in Northeast of South Khorasan Province with the aim of quantifying the vegetative resilience on behalf of the ecosystem health in response to long-term precipitation changes. First, the annual precipitation standardization was performed during a thirty-year period by the SPI method. Then, the average variation in TNDVI index obtained from the Landsat satellite images was examined and the resilience was tested by calculating the four effective factors (amplitude, malleability, damping and hysteresis). According to the results, the amplitude in the survey period was $6.04 \%$ and the vegetation has had different values of damping over the years. The most prominent example of vegetation resilience occurred between 1986 and 1996, with malleability of 0.7 and damping of zero. Vegetation in this period, after the elimination of drought effects (1986), has not only returned to the amount of vegetation of reference year with severe precipitation (1996) but also increased by $0.25 \%$. This increase, as the index of hysteresis, has been presented for the first time in the ecosystem health discussion quantitatively in the present study. A set of quantitative calculations showed that despite reduced annual precipitation and drought events, the vegetation has been able to maintain its resilience, which indicates the health of vegetation in the studied ecosystem.
\end{abstract}

Key words: ecosystem health, resilience, hysteresis, quantitative study, remote sensing.

\section{Introduction}

Vegetation resilience is an important factor in ecosystem health, and a variety of environmental disorders can disrupt it. The term resilience was first introduced in 1970 in the study 
of ecological systems (Holling, 1973) and demonstrates the ability of the ecosystem to maintain its performance in the face of environmental disorders (Elmqviste et al., 2003). A resilience-based system is not only equipped with a disorder adjustment mechanism but also has the potential to benefit from changes in a way that lead to creating an opportunity for development, innovation, and updating (Rockstrom, 2003). Therefore, when a change occurs, the resilience provides the needed conditions for restarting and reorganization (Gunderson, Holling, 2002; Friend, Moench, 2013). If this goes beyond the disturbing forces, the system will have the power to return to maximum vegetation density with least erosion effects, otherwise the system will be vulnerable to the change that was created and could be controlled (Kasperson R.E., Kasperson J.X., 2001). These predictions have been confirmed and proven in the recent field studies by Abrahams et al. (1995), as well as Puigdefábregas and Sánchez (1996). Natural calamities such as flood, earthquake and drought change the process of evolution and the sequence of nature. In contrast to these disorders, the nature has complex and adaptive methods to deal with such occurrences (Holling, 1986). But quantifying the effect of these occurrences can be difficult because the current state of the system depends on its previous state (Carpenter et al., 2001). However, examining the characteristics of the ecosystem on large spatial and temporal scales is one way that can be used to track the effects of disorders in the landscapes. Ecosystem indicators such as vegetation status can be analysed using information, software, and spatial methods (such as remote sensing techniques) to measure the resilience (Washington-Allen et al., 2008). Vegetation is one of the main components of natural ecosystems, where degradation can be observed as loss of diversity and change in vegetation type compared to the initial state of the landscape density (Ringrose et al., 1990; Goheen et al., 2007). Normalized difference vegetation index (NDVI) is useful particularly for measuring the amount of photosynthesis of biomass in semi-arid and savannah areas (Martiny et al., 2006), where vegetation is not high (Richard, Poccard, 1998). At the same time, there are potential limitations in using the NDVI index in these areas, depending on the type and reflection of the soil (Farrar et al., 1994). The provision of additional facilities (MSS and TM Landsat multidimensional sensors) have provided the appropriate spatial scale as the ideal point for comparative regional research for the analysis of long-term changes (Griffiths, Philippot, 2013). These limitations are now minimized in Landsat 7 and 8 satellites with ETM +, OLI, and TRIS sensors and image quality enhancement. Griffiths and Philippot (2013) examined the soil health by examining the status of microbes available in it under environmental and managerial disorders, and soil contamination with heavy metals qualitatively, and concluded that the soil stability and resilience do not depend on the percentage of microbial species, but on the functional characteristics in the soil structure. Westman and O'Leary (1986) have developed 4 criteria of environmental malleability, including the time to return to the reference, amplitude, malleability and damping. In this study, the response of coastal plants in southern California was used against fire disorder. This study was carried out using the data obtained from field observations and a simulation model. The values of the criteria were taken using graphic charts. Washington-Allen et al. (2008) and Cui et al. (2013) examined the vegetative resilience qualitatively by plotting the mean-variance plot in Bolivia, in America and South Africa, respectively. Also, Pricope et al. (2015) examined the changes in the vegetation of Savannah's landscape due to the flood and fire in South Africa 
qualitatively, but it is only a history of quantifying the ecological resilience using satellite images and exact mathematical equations related to the study by Washington-Allen et al. (2008) on the vegetation in South Africa. This study was conducted on the total vegetation and various cover classes using TNDVI Vegetation Index and Landsat satellite images from 1972 to 1987. Three factors of amplitude, malleability and damping were examined and compared in this study on the vegetation. Among the existing vegetation classes, the meadow showed the highest amount of resilience and malleability compared to the other vegetation and was introduced as a key source and indigenous vegetation survived from the climate change in the region.

\section{Material and methods}

The study region with an area of $2193 \mathrm{~km}^{2}$ is located at $33^{\circ} 19^{\prime}-33^{\circ} 22^{\prime} \mathrm{N}, 60^{\circ} 23^{\prime}-60^{\circ} 40^{\prime} \mathrm{E}$ in the Northeast of South Khorasan Province (Fig. 1). The climate of the region based on the Amberge categorization is cold and arid, and the average annual precipitation is $160 \mathrm{~mm}$. Within the scope of the study, three uses of pasture, forest and woodland can be distinguished; in each of them, according to the soil and altitude conditions, herbaceous, bush, tree and shrub species are established. For example, you can see herbaceous species of Artemisia sp., Ephedra strobilacea, Astragalus sp., Stipagrostis plumosa and some saline soil like Seidlitzia rosmarin, Salsola tomentosa in pastures. Forest species include Haloxylon ammodendron, Tamarix sp., Amygdalus scoparia, Pistacia atlantica, Ammodendron persicum, which have created the thin forests of the study area.

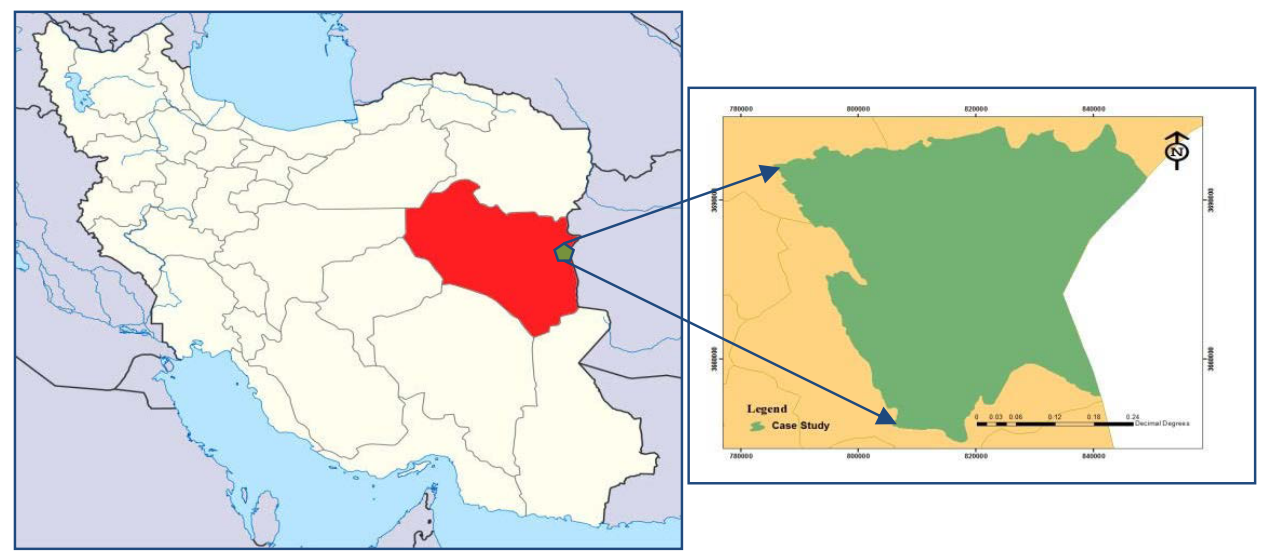

Fig. 1. Location of study area.

Using the daily precipitation data from 15 meteorological stations around the study area (Fig. 2), annual precipitation was extracted over the course of thirty years (1986-2015). Then, the data were interpolated in software ArcGIS for the study area using IDW method and by standard precipitation index (SPI), dry, wet and normal years were determined. In order to complete the years without any precipitation data of each station, correlation with neighbouring stations and software SPSS were used.

From the Landsat 5 and 7 satellite images' archives of the study area, for each year of the thirty-year study period, an image was taken for the period starting from June 15 to July 15, with permanent vegetation under the best growing condition. Finally, 24 images were available (Table 1). 
Using the software ENVI and ArcGIS, after making the required satellite images' corrections, NDVI and TNDVI vegetation indices' maps were provided for each image. NDVI is a normalized vegetation difference index used in analyses, remote sensing measurements and vegetation assessment of an area, and its numerical value varies from 1 to $1+$ in satellite images per pixel (equation 1).

This index is calculated using equation 1 , where $\mathrm{R}$ is the red band of the electromagnetic spectrum and NIR is the infrared band near the electromagnetic spectrum.

$$
\mathrm{NDVI}=\mathrm{NIR}-\mathrm{R} / \mathrm{NIR}+\mathrm{R}
$$

Removal of negative values and increasing the numerical range of this index was done with the aim of facilitating quantitative examination and analysis in the process of long-term vegetation changes, by converting NDVI index to TNDVI index with a range from zero to 100. In all the subsequent studies, TNDVI vegetation index was used. TNDVI vegetation index is calculated using equation 2 .

$$
\text { TNDVI }=50(\mathrm{NDVI}+1)
$$

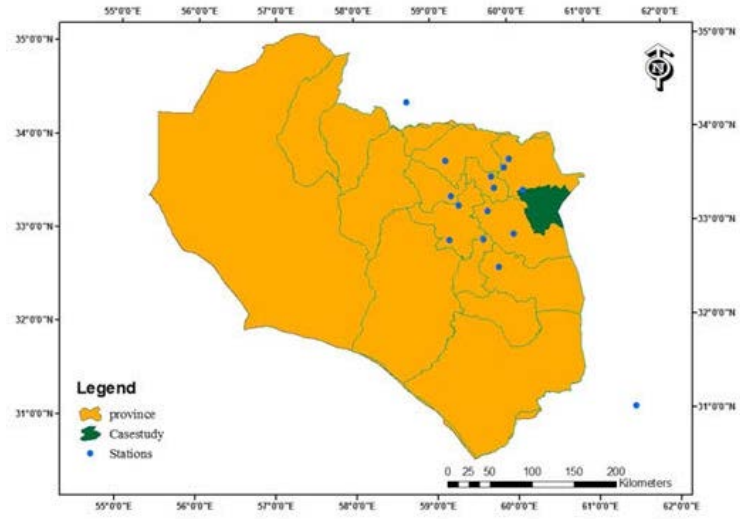

Fig. 2. Location of meteorological stations in study region.

$\mathrm{T}$ a b l e 1. Characterize of satellite images.

\begin{tabular}{|l|c|r|}
\hline Scanner & Satellite & \multicolumn{1}{c|}{ Study Term } \\
\hline TM & Landsat 5 & $1986-1999$ \\
\hline ETM+ & Landsat 7 & $2000-2015$ \\
\hline NO Image & $1988-1994-1995-1997-1999-2006$ \\
\hline
\end{tabular}

In order to examine and quantify ecologically resilience-related changes, it is necessary to recognize factors such as amplitude, malleability, damping and hysteresis. These concepts and methods of calculating them are presented by Washington-Allen et al. (2008), which will be mentioned later in the article. After preparing the TNDVI vegetation index maps for each year using the software ArcGIS, the average values of this index were extracted in each image and all calculations were manually performed using this parameter. The unit of measurement of the average vegetation index of TNDVI and all factors of vegetation's resilience is $\%$.

1. The factor amplitude $=\mid \Delta$ TNDVIA $\mid$

The amount of change after the disorder stage, or simultaneously that the system may return to the reference stage or not, and is calculated according to equation 3 , where $\mathrm{D}$ is the year of occurrence of the disorder and $\mathrm{R}$ is the reference year.

$$
\mid \Delta \text { TNDVI } \mathrm{A} \mid=\text { TNDVI } \mathrm{D}-\text { TNDVI } \mathrm{R}
$$

2. The factor malleability $=(\triangle$ TNDVI $M)$

The amount of vegetation compensation (recovery) in one or a few years' average after the removal of disorder and calculated according to equation 4.

$\Delta$ TNDVI M = | $\Delta$ TNDVI A $\mid$ - (\{TNDVI (year of removal of the disorder effect), ...TNDVI (date+1) $\}$ - TNDVI R) (4)

Washington-Allen et al. (2008) in their study stated that the return to the reference state occurs, if the factor of malleability is equal to or smaller than zero.

\section{$(\Delta$ TNDVI $\mathrm{M} \leq 0)$}

3. The factor hysteresis

Increasing the vegetation beyond the range of the reference state, which is created in the opposite direction of the path of destruction. 


\section{The factor damping}

A part of the change in vegetation that has not returned to the reference state after a disorder.

Our investigations showed that equation 4 does not provide the expected result in the calculation of the factor of malleability. So, we proposed new equations and added additional descriptions. In the research method, modified equations were used.

When a disorder occurs, particularly in the vegetation, the destructive effect of the disorder according to the conditions may be observed in the year of occurrence or delayed in the subsequent year(s). So, the term 'the year of the effect of a disorder' was used instead of the term 'the year of occurrence' in the equations.

To determine how a vegetation returns to the reference after the removal of the disorder effect, equation 5 was used instead of equation 4, where $\mathrm{R}^{\prime}$ represents a recovery. The result of this equation proportional to being zero, positive or negative, represents different conditions of vegetation recovery. It should be kept in mind that this equation does not provide the amount of vegetative malleability.

$|\triangle T N D V I A|-(\{T N D V I R '$ (year of removal of the disorder effect) - TNDVID (year of the disorder effect) $\{=(0,+,-)(5)$

1. If the result of this equation is zero, it indicates the recovery of the vegetation exactly to the reference state.

2. If the result is a negative number, it indicates that not only the vegetation returned to the reference state but also increased in comparison to the reference. This amount of increase is called hysteresis.

In the states of 1 and 2 , the numerical value of the factor of malleability is equal to the amplitude.

TNDVI $\mathrm{M}=\mid \Delta$ TNDVI $\mathrm{A} \mid$

3. If the result of the equation is a positive number, it indicates that the vegetation has moved towards the reference state but has not reached it, and the numerical value obtained from equation 5 shows the amount of vegetation damping compared to the reference. In this case, Equation 6 should be used to obtain the malleability value.

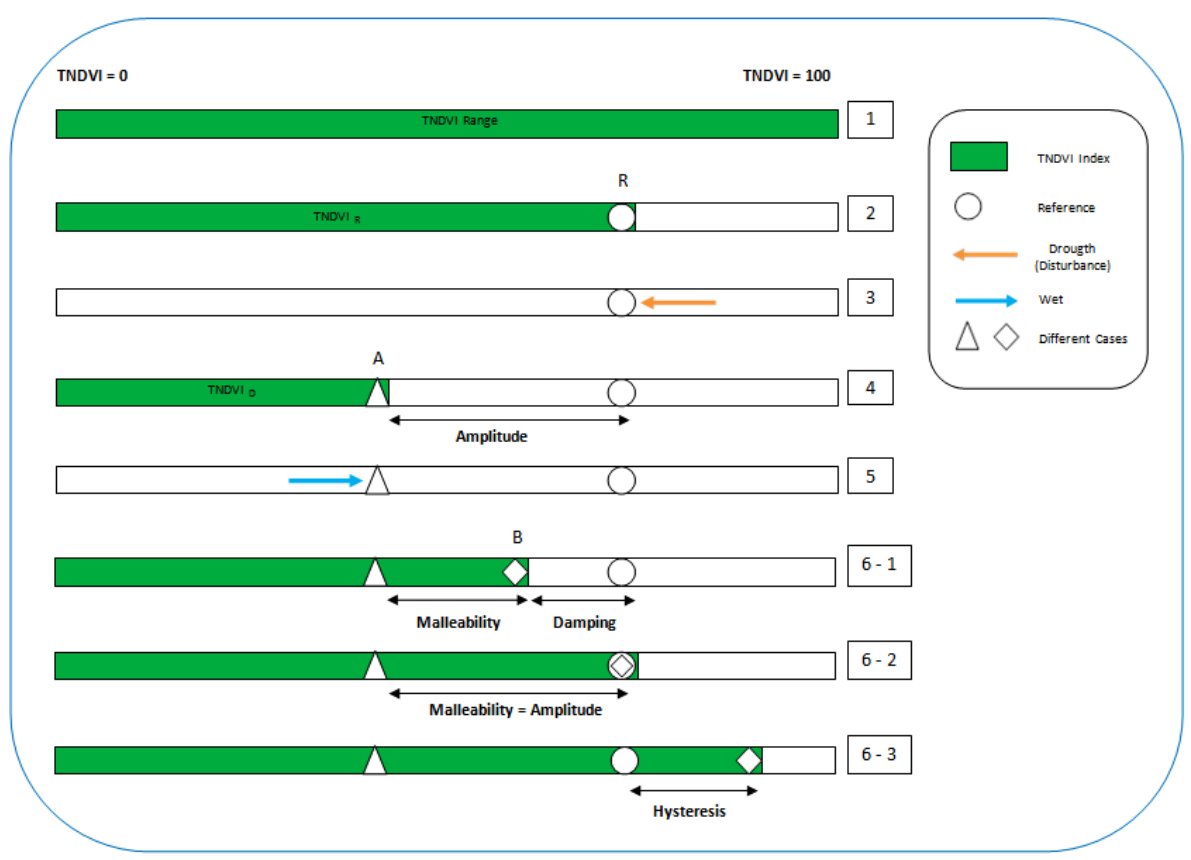

Fig. 3. Conceptual chart for resilience parameters. 
To calculate the factors of malleability, damping and hysteresis in each disorder occurrence, three years are required for comparison, including reference year, year of the occurrence effect, and average of one year or several years after the occurrence is resolved. The concept of the factors studied and the corrective comments are given in Fig. 3 in the form of a conceptual chart.

\section{Results and discussion}

Comparison of annual precipitation variations in the thirty-year series (1986-2015) indicates two approximate wet and dry periods. The wet period is related to the first fourteen years of the time series (1986-1999) and the dry period is related to the last sixteen years (2000-2015) (Fig. 4).

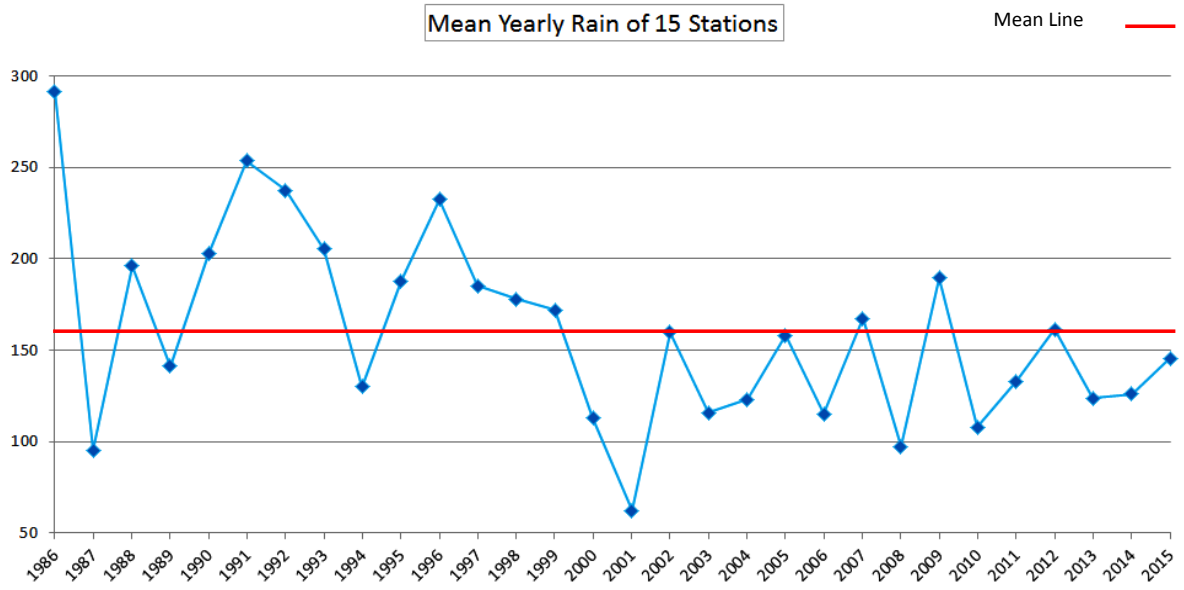

Fig. 4. Mean annual precipitation changes.

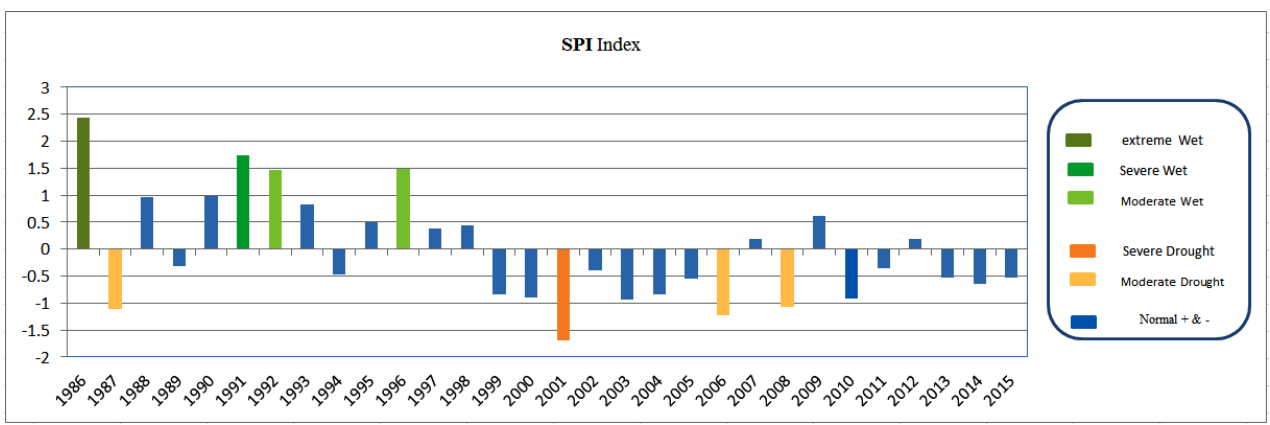

Fig. 5. Comparison of Standard Precipitation Index (SPI) and the severity of events within the study area based on the Interpolation (IDW). 
Figure 5 shows the annual precipitation levels in the thirty-year series of the study area based on Standard Precipitation Index (SPI). Precipitation and drought with different intensities as well as the annual precipitation changes in the normal years are occurrences that are given in this Figure.

This table shows 4 precipitation occurrences with different intensities including 1 case of very intense precipitation (1986), 1 case of intense precipitation (1991) and 2 cases of moderate precipitation (1996 and 1992). Also, 4 drought occurrences including 1 case of intense drought (2001) and 3 cases of moderate drought (1987, 2006 and 2008) also occurred. All precipitation occurrences are related to the first half and most drought occurrences are related to the second half of the studied period. According to the distribution of SPI index,

T a b l e 2. TNDVI index values, annual precipitation and SPI index classes of the study area.

\begin{tabular}{|c|c|c|c|c|}
\hline Row & Year & Mean TNDVI & annual precipitation & SPI index classes \\
\hline 1 & 1986 & 49.37 & 291.22 & Extreme Wet \\
\hline 2 & 1987 & 48.96 & 95.26 & Moderate Wet \\
\hline 3 & 1988 & No Image & 196.24 & Normal + \\
\hline 4 & 1989 & 48.96 & 141.2 & Normal - \\
\hline 5 & 1990 & 48.85 & 202.94 & Normal + \\
\hline 6 & 1991 & 48.73 & 253.67 & Sever Wet \\
\hline 7 & 1992 & 48.92 & 237.51 & Moderate Wet \\
\hline 8 & 1993 & 49.03 & 205.36 & Normal + \\
\hline 9 & 1994 & No Image & 129.97 & Normal - \\
\hline 10 & 1995 & No Image & 188.02 & Normal + \\
\hline 11 & 1996 & 49.62 & 232.48 & Moderate Wet \\
\hline 12 & 1997 & No Image & 185.2 & Normal + \\
\hline 13 & 1998 & 49.2 & 177.88 & Normal + \\
\hline 14 & 1999 & No Image & 171.9 & Normal - \\
\hline 15 & 2000 & 47.71 & 112.97 & Normal - \\
\hline 16 & 2001 & 43.77 & 62.38 & Severe Drought \\
\hline 17 & 2002 & 43.94 & 159.91 & Normal - \\
\hline 18 & 2003 & 44.47 & 115.79 & Normal - \\
\hline 19 & 2004 & 43.49 & 123.07 & Normal - \\
\hline 20 & 2005 & 44.26 & 158.22 & Normal - \\
\hline 21 & 2006 & No Image & 115.08 & Moderate Drought \\
\hline 22 & 2007 & 44.41 & 167.41 & Normal + \\
\hline 23 & 2008 & 43.81 & 97.23 & Moderate Drought \\
\hline 24 & 2009 & 44.52 & 189.53 & Normal + \\
\hline 25 & 2010 & 43.58 & 108.07 & Normal - \\
\hline 26 & 2011 & 43.84 & 132.93 & Normal - \\
\hline 27 & 2012 & 43.91 & 161.37 & Normal + \\
\hline 28 & 2013 & 43.84 & 123.72 & Normal - \\
\hline 29 & 2014 & 43.76 & 126.1 & Normal - \\
\hline 30 & 2015 & 44.28 & 145.56 & Normal - \\
\hline
\end{tabular}


precipitation has occurred in years when precipitation has exceeded $232 \mathrm{~mm}$, and drought has occurred with an annual precipitation of $95 \mathrm{~mm}$. The interval between these two values represents the normal state. The number zero in SPI index is equivalent to the average precipitation of 160.3. The value between the average and precipitation is wet normal (normal + ) and less than the value to drought occurrence is dry normal (normal -). Precipitation variations, especially in the dry period and drought occurrence in the year of occurrence or delayed, have had undesirable effects on the average vegetation of the study area. Table 2 shows the average amount of vegetation in the study area in 24 years of the thirty years with good satellite images.

In the first case, the vegetation resilience was examined over the entire thirty-year period. The year 1986 was the first year of study reference of the vegetation changes; the year 2010 was the year of decline in vegetation to the lowest amount during the thirty years of study period; and the year 2015 was the final year of the studied period. The amount of vegetation

$\mathrm{T} \mathrm{a} \mathrm{b} \mathrm{l} \mathrm{e} \mathrm{3.} \mathrm{Quantitative} \mathrm{examination} \mathrm{of} \mathrm{the} \mathrm{resilience} \mathrm{factors} \mathrm{in} \mathrm{the} \mathrm{selected} \mathrm{years.}$

\begin{tabular}{|c|c|c|c|c|c|c|}
\hline \multicolumn{7}{|c|}{ TNDVI resilience factors in 1986-2015 (Whole time series) } \\
\hline \multirow{6}{*}{ 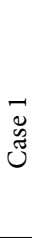 } & \multirow{2}{*}{ Year } & \multicolumn{5}{|c|}{ Mean TNDVI (\%) } \\
\hline & & Amount & Amplitude & Malleability & Damping & Hysteresis \\
\hline & 1986 & 49.37 & - & - & - & - \\
\hline & 2010 & 43.58 & 5.79 & - & - & - \\
\hline & 2015 & 44.28 & - & 0.7 & 5.09 & 0 \\
\hline & Legend & \multicolumn{2}{|c|}{ Reference $=1986$} & \multicolumn{2}{|c|}{ Reduce in vegetation index $=2010$} & End of time series $=2015$ \\
\hline \multicolumn{7}{|c|}{ TNDVI resilience factors in 1986-1996 (Wet time series). } \\
\hline \multirow{6}{*}{ 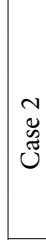 } & \multirow{2}{*}{ Year } & \multicolumn{5}{|c|}{ Mean TNDVI (\%) } \\
\hline & & Amount & Amplitude & malleability & Damping & Hysteresis \\
\hline & 1986 & 49.37 & - & - & - & - \\
\hline & 1991 & 48.73 & 0.64 & - & - & - \\
\hline & 1996 & 49.62 & - & 0.64 & 0 & 0.25 \\
\hline & Legend & \multicolumn{2}{|c|}{ Reference $=1986$} & \multicolumn{2}{|c|}{ Reduce in vegetatio } & Returned to the reference $=1996$ \\
\hline \multicolumn{7}{|c|}{ TNDVI resilience factors in 2000-2003 (Drought time series). } \\
\hline \multirow{6}{*}{ 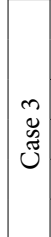 } & \multirow{2}{*}{ Year } & \multicolumn{5}{|c|}{ Mean TNDVI (\%) } \\
\hline & & Amount & Amplitude & malleability & Damping & Hysteresis \\
\hline & 2000 & 47.71 & - & - & - & - \\
\hline & 2001 & 43.77 & 3.94 & - & - & - \\
\hline & 2003 & 44.47 & - & 0.7 & 3.24 & 0 \\
\hline & Legend & \multicolumn{2}{|c|}{ Reference $=2000$} & \multicolumn{2}{|c|}{ Reduce in vegetation indes } & Returned to the reference $=2003$ \\
\hline \multicolumn{7}{|c|}{ TNDVI resilience factors in 2003-2009 (Drought time series). } \\
\hline \multirow{6}{*}{ 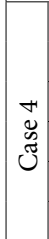 } & \multirow{2}{*}{ Year } & \multicolumn{5}{|c|}{ Mean TNDVI (\%) } \\
\hline & & Amount & Amplitude & malleability & Damping & Hysteresis \\
\hline & 2003 & 44.47 & - & - & - & - \\
\hline & 2008 & 43.81 & 0.33 & - & - & - \\
\hline & 2009 & 44.52 & - & 0.33 & 0 & 0.05 \\
\hline & Legend & \multicolumn{2}{|c|}{ Reference $=2003$} & \multicolumn{2}{|c|}{ Reduce in vegetation index $=2008$} & Returned to the reference $=2009$ \\
\hline
\end{tabular}


in 1986 was $49.37 \%$, which, by reduced precipitation, reached the lowest amount of $43.58 \%$ in 2010. By increasing the moisture in 2015, it returned to $0.7 \%$ of the reference vegetation but did not reach it. Therefore, the amount of vegetation damping in this recovery was $5.09 \%$. Despite this, the vegetation also experienced resilience in this case.

The second case is related to the wet period between 1986 and 1996, in which, the year 1986 is the reference year for the comparison of vegetation changes. In 1991, the vegetation was reduced due to the reduced precipitation and drought. The interval between the value of the reference vegetation and the year of the disorder effect (1991) was the amplitude of the vegetation changes between these two years, and its value during this period was 0.64 percent. In 1996, the conditions had shifted to rising precipitation, resulting in increased vegetation. Vegetation in this year, in addition to being returned to the reference state $(0.64 \%)$, had increased by $0.25 \%$ compared to the reference (the factor hysteresis). In this period, because the vegetation completely returned to the reference, the damping index, the difference between the amplitude and malleability indices, was zero. The third and fourth cases are related to the vegetation recovery to the reference in the dry period, and despite the dominance of dry conditions, the vegetation's recovery to the reference state is also observed. In case 3 , the resilience reproved in the dry period between 2000 and 2003, and 2001 was faced with intense drought.

In the fourth case, the vegetation, in addition to returning to the reference state, had $0.05 \%$ hysteresis.

It is reminded, among the cases presented, only 4 cases of vegetation changes were in the study period, which were presented in the study area to calculate the quadruple factors and prove the presence of the vegetation resilience in the study area. In the studied period, we can examine more similar cases and calculate the vegetation resilience.

\section{Conclusion}

Awareness of the health status of the vegetation and its response to long-term precipitation changes and environmental disorders, such as drought occurrence, ensure the success of the managerial plans for renewable natural resources. A quantitative study of the vegetation resilience was first performed as the control of the ecosystem health in 2008 by WashingtonAllen et al. in South Africa with an average precipitation of $402 \mathrm{~mm}$, and was able to show the natural vegetation resilience in the study area by calculating the three factors of amplitude, malleability and damping. Our study is the second study on quantifying the vegetation resilience and the first study under dry climatic conditions in Asia (an average annual precipitation of $160 \mathrm{~mm}$ ) conducted in Iran by calculating four factors related to the resilience, and is the first study that has presented the factor hysteresis in the calculations. Given the large difference in the average annual precipitation in the two studied regions, both of which are presented as arid climates, the present study can be considered as a unique example in the ecosystem health discussion in regions with similar conditions. Despite the difficult conditions and the consistency, the native vegetation of the study area has been able to return the reference state not only by resolving the disorder relatively, but also it has experienced hysteresis stage. With the presence of such amazing protective and consistent mechanisms in 
the vegetation of arid regions, it is possible to maintain and restore these regions by proper managerial plans.

\section{References}

Abrahams, A.D., Parsons, A.J. \& Wainwright J. (1995). Effects of vegetation change on interrill runoff and erosion, Walnut Gulch, southern Arizona. Geomorphology, 13, 37-48. DOI: 10.1016/0169-555X(95)00027-3.

Carpenter, S.R., Walker, B.H., Anderies, J.M. \& Abel N. (2001). From metaphor to measurement: Resilience of what to what? Ecosystems, 4, 765-781. DOI: 10.1007/s10021-001-0044-9.

Cui, X., Gibbes, C., Southworth, J. \& Waylen P. (2013). Using remote sensing to quantify vegetation change and ecological resilience in a semi-arid system. Journal of Land, 2, 108-130. DOI: 10.3390/land22020108.

Elmqvist, T., Folke, C., Nystrom M., Peterson, G., Bengtsson, J., Walker, B. \& Norberg J. (2003). Response diversity, ecosystem change, and resilience. Frontiers in Ecology and the Environment, 1, 488-494. DOI: 10.1890/15409295(2003)001[0488:RDECAR]3.0.CO;2.

Farrar, T.J., Nicholson, S.E. \& Lare A.R. (1994). The influence of soil type on the relationships between NDVI, rainfall, and soil moisture in semiarid Botswana. II. NDVI response to soil moisture. Remote Sens. Environ., 50, 121-133. DOI: 10.1016/0034-4257(94)90039-6.

Friend, R. \& Moench M. (2013). What is the purpose of urban climate resilience? Implications for addressing poverty and vulnerability. Urban Climate, 6, 98-113. DOI: 10.1016/j.uclim.2013.09.002.

Goheen, J., Young, T., Keesing, F. \& Palmer T. (2007). Consequences of herbivory by native ungulates for the reproduction of a savanna tree. J. Ecol., 95, 129-138. DOI: 10.1111/j.1365-2745.2006.01196.x.

Griffiths, B.S. \& Philippot L. (2013). Insights into the resistance and resilience of the soil microbial community. FEMS Microbiol. Rev., 37, 112-129. DOI: 10.1111/j.1574 6976.2012.00343.x.

Gunderson, L.H. \& Holling C.S. (2002). Panarchy: Understanding transformations in human and natural systems. Washington: Island Press.

Holling, C.S. (1973). Resilience and stability of ecological systems. Annu. Rev. Ecol. Syst., 4, 1-23. DOI: 10.1146/ annurev.es.04.110173.000245.

Holling, C.S. (1986). The resilience of terrestrial ecosystems: Local surprise and global change. In W.C. Clark \& R.E. Munn (Eds.), Sustainable development of the biosphere (pp. 292-320). Cambridge: Cambridge University Press.

Kasperson, R.E. \& Kasperson J.X. (2001). Climate change, vulnerability and social justice. Stockholm: Stockholm Environment Institute.

Martiny, N., Camberlin, P., Richard, Y. \& Philippon N. (2006). Compared regimes of NDVI and rainfall in semi-arid regions of Africa. Int. J. Remote Sens., 27, 5201-5223. DOI: 10.1080/01431160600567787.

Puigdefábregas, J. \& Sánchez G. (1996). Geomorphological implications of vegetation patchiness on semi-arid slopes. In M.G. Anderson \& S.M. Brooks (Eds.), Advances in hillslope processes (pp. 1027-1060). Wiley.

Pricope, N.G., Gaughan, A.E., All, J.D., Binford, M.W. \& Rutina L.P. (2015). Spatio-temporal analysis of vegetation dynamics in relation to shifting inundation and fire regimes: Disentangling environmental variability from Land management decisions in a Southern African transboundary watershed. Land, 4, 627-655. DOI: 10.3390/ land4030627.

Richard, Y. \& Poccard I. (1998). A statistical study of NDVI sensitivity to seasonal and interannual rainfall variations in Southern Africa. Int. J. Remote Sens., 19, 2907-2920. DOI: 10.1080/014311698214343.

Ringrose, S., Matheson, W., Tempest, F. \& Boyle T. (1990). The development and causes of range degradation features in southeast Botswana using multi-temporal Landsat MSS imagery. Photogrammetric Engineering and Remote Sensing, 56, 1253-1262.

Rockström, J. (2003). Resilience building and water demand management for drought mitigation. Physics and Chemistry of the Earth, 28, 869-877. DOI: 10.1016j.pce.2003. 08.009.

Washington-Allen, R.A., Ramsey, R., West, N.E. \& Norton B.E. (2008). Quantification of the ecological resilience of drylands using digital remote sensing. Ecology and Society, 13, 33-37. http://www.ecologyandsociety.org/ vol13/iss1/art33/

Westman, W.E. \& O'Leary J.F. (1986). Measures of resilience: the response of coastal sage scrub to fire. Vegetatio, 65(3), 179-189. DOI: 10.1007/BF000444818. 